\title{
Generalized Muscle Weakness, CTCAE
}

National Cancer Institute

\section{Source}

National Cancer Institute. Generalized Muscle Weakness, CT CAE. NCI Thesaurus. Code C143514.

A disorder characterized by a reduction in the strength of muscles in multiple anatomic sites. 